\title{
Regional analysis of diabetic retinopathy and co-existing social and demographic factors in the overall population of Poland
}

\author{
Milena Kozioł ${ }^{1}$, Michał S. Nowak ${ }^{2,3}$, Beata Koń ${ }^{4}$, Monika Udziela ${ }^{5}$, Jacek P. Szaflik ${ }^{5}$
}

\author{
${ }^{1}$ Polish Ministry of Health, Warsaw, Poland \\ ${ }^{2}$ Provisus Eye Clinic, Czestochowa, Poland \\ ${ }^{3}$ Saint Family Hospital Medical Center, Lodz, Poland \\ ${ }^{4}$ Collegium of Economic Analysis, SGH Warsaw School of Economics, Warsaw, Poland \\ ${ }^{5}$ Department of Ophthalmology, Medical University of Warsaw, Public Ophthalmic \\ Clinical Hospital (SPKSO), Warsaw, Poland
}

Submitted: 20 September 2020, Accepted: 7 December 2020

Online publication: 22 May 2021

Arch Med Sci 2022; 18 (2): 320-327

DOI: https://doi.org/10.5114/aoms/131264

Copyright (c) 2021 Termedia \& Banach

\author{
Corresponding author: \\ Milena Kozioł \\ Polish Ministry of Health \\ Warsaw, Poland \\ E-mail: koziol.milena@gmail. \\ com
}

\begin{abstract}
Introduction: The aim of our study was to analyse the regional differences in diabetic retinopathy (DR) prevalence and its co-existing social and demographic factors in the overall population of Poland in the year 2017.

Material and methods: Data from all levels of healthcare services at public and private institutions recorded in the National Health Fund database were evaluated. International Classification of Diseases codes were used to identify patients with type 1 and type 2 diabetes mellitus (DM) and with DR. Moran's I statistics and Spatial Autoregressive (SAR) model allowed us to understand the distribution of DR prevalence and its possible association with environmental and demographic exposures.

Results: In total, 310,815 individuals with diabetic retinopathy (DR) were diagnosed in the year 2017 in Poland. Of them, 174,384 (56.11\%) were women, 221,144 (71.15\%) lived in urban areas, and 40,231 (12.94\%) and $270,584(87.06 \%)$ had type 1 and type 2 DM, respectively. The analysis of the SAR model showed that the significant factors for the occurrence of DR in particular counties were a higher level of average income and a higher number of ophthalmologic consultations per 10,000 adults.

Conclusions: The analyses of social, demographic, and systemic factors co-existing with DR revealed that level of income and access to ophthalmologic and diabetic services are crucial in DR prevalence in Poland.
\end{abstract}

Key words: diabetic retinopathy, diabetes mellitus, epidemiology, public health, Moran's I statistics.

\section{Introduction}

According to International Diabetes Federation (IDF), the global population with diabetes mellitus (DM) reached 451 million in the year 2017 (age 18-99 years), and it is estimated that by the year 2045 this number will increase to 693 million people around the world [1]. We divide complications of DM into macro- and micro-vascular related, e.g. macro-vascular - coronary heart disease (CHD), myocardial infarction, peripheral arterial disease (PAD), and stroke; micro-vascular - diabetic retinopathy (DR), and nephropathy [2-4]. There are also diabetes-induced syndromes 
like diabetic foot syndrome, which has recently been associated with adverse effects on brain function $[5,6]$. The incidence of DR is falling, probably due to better management of glucose levels, lipid abnormalities, and hypertension. Nonetheless, DR is still the most vision-threatening complication, and the crude prevalence (at all ages) of visual impairment and blindness caused by DR increased significantly between the years 1990 and 2015 with respect to the global population [7-9]. There is a great number of articles concerning the prevalence, developing factors, and current treatment strategies of DR, and geographical analysis with advanced statistical methods could result in interesting new conclusions in terms of the origin of the disease and the organization of healthcare systems. However, the number of studies showing the geographical analysis of the prevalence of DR and co-existing social and demographic factors is limited [10-12].

The logic behind using geography to study disease or health care comes from the realization of factors resulting in non-uniformity of disease distribution [13-15]. These factors include social, economic, environmental, and genetic ones. All these factors may have spatial distributions influencing the incidence of a disease. Geographic information systems with spatial analytical methods are helpful in the study of health status and health care delivery [16]. That approach is extremely useful in the case of analysing outbreaks of contagious diseases like malaria or mumps $[17,18]$. However, the literature review covers the large use of such methods in case of non-contiguous diseases, e.g. leukaemia [19]. This approach allows us to statistically verify the regions of either extremely high or low prevalence of diseases. In addition, the knowledge of spatial properties and disease patterns allows the planning of a health care service in a rational manner and meets the needs of patients.

The aim of our study was to analyse the regional differences in diabetic retinopathy prevalence and its co-existing social and demographic factors in the overall population of Poland in the year 2017.

\section{Material and methods}

The present study was co-financed by the European Union funds through the European Social Fund under the Operational Program of Knowledge Education and Development and was a part of the Polish Ministry of Health project "Maps of Healthcare Needs - Database of Systemic and Implementation Analyses" [20, 21]. The study design was a nation-wide survey. The Republic of Poland is the largest Central European country, with a population of $38,422,346$ people (in the year 2017), mostly of middle socio-economic status [22]. The area of Poland is $312,679 \mathrm{~km}^{2}$, and Poland is divided into 16 voivodships and 380 counties in terms of administrative division. The population data and socio-demographic information of the counties for the year 2017 were obtained from the Central Statistical Office of Poland [22]. For the purpose of this study, the Polish National Health Fund (NHF) database, the only public insurer in Poland, was retrospectively analysed [23]. The NHF database records data from all levels of healthcare services at public and private institutions in Poland and compiles both medical and personal data including age, sex, place of residence, and identification number (PESEL) of each individual patient. The medical data include diagnoses coded according to the International Classification of Diseases, 10th Revision (ICD10) and unique NHF codes. The NHF database also contains the records of all medications purchased by the Polish patients in pharmacies, which were reimbursed by NHF. In the first part of the study, for each patient in the years 2013-2017, DM type 1 and type 2 was identified with ICD-10 codes E10 and $\mathrm{E} 11$, respectively. All diagnoses were then confirmed if the patient purchased antidiabetic drugs (and/or insulin) during the study period. Following that, DR was identified in DM patients using the ICD-10 codes $\mathrm{H} 36.0, \mathrm{H} 36.8$, and $\mathrm{H} 35.8$ during 2013-2017. The overall prevalence of DR and DM in Poland in 2017 was the total number of individuals who were alive on 31 December 2017 and occurred in the NHF database during 2013-2017 with DR and DM, respectively.

\section{Statistical analysis}

For statistical analysis, the socio-demographic data of all patients including age, sex, and place of residence were anonymously recorded. In the first part of the statistical analysis, the spatial analysis was conducted, which provides opportunities to understand the spatial distribution of diseases and the possible association between its environmental and demographic exposures [13, 17-19]. There are numerous methods for testing clustering in data. The method that is widely used by epidemiologists is the one developed by Patrick Alfred Pierce Moran [11]. Moran's Index is a weighted correlation coefficient that is used to measure deviation from spatial randomness and has the form as below:

$$
I=\frac{N}{\sum_{i} \Sigma_{j} w_{i j}} \frac{\sum_{i} \Sigma_{j} w_{i j}\left(x_{i}-\bar{x}\right)\left(x_{j}-\bar{x}\right)}{\sum_{i}\left(x_{i}-\bar{x}\right)^{2}}
$$

where $N$ is the number of spatial units, in this study denotes a number of counties (380): $x_{i}$ and $x_{j}$ are values of a variable of interest (retin- 
opathy prevalence per $10 \mathrm{k}$ population) for $i, j=$ $1, \ldots, 380, \bar{x}$ is the mean of variable of interest, $w_{i j}$ denotes an element of spatial weights matrix, $w_{i j}$ is zero either when $i=j$ or 2 counties $i, j$ are totally separated in terms of the common border (queen neighbourhood). When 2 counties share a border, the weight is equal to 1 . The values of I range from -1 (perfect dispersion) to +1 (perfect clustering) [24-26].

The next part of the statistical analysis was to identify the variables explaining the differences in retinopathy prevalence values among counties. It was important to consider a spatial approach because the assumption of the observation's independence is no longer valid. Due to this argument the Spatial Autoregressive (SAR) model was used. The SAR model is an OLS (ordinary least squares) method with correction related to autocorrelation defined by the spatial-weights matrix [19]. The factors used to explain the differences in the prevalence in diabetic retinopathy in the counties of Poland were grouped into 3 categories: epidemiological, sociodemographic, and accessibility/ quality. All details of the factors used to explain the differences in the prevalence of diabetic retinopathy in the counties of Poland are presented in Table I. To build the model, each variable was transformed, i.e. divided by the median value of the variable, which enables us to interpret the results of the model in terms of median values, which is especially useful, in particular when the factors are in different scales. Before building the model the normality of the dependent variable was verified. Box-Cox transformation and Shap-
iro-Wilk test ( $p=0.08$ ) revealed that the logarithmic transformation met the assumptions of normality. In addition, the collinearity of explanatory variables was verified. The value of the variance inflation factor (VIF) was up to 3 for each variable that indicated a lack of collinearity. The adjusted $R^{2}$ was used to validate the goodness of the model. R statistical software V. 3.5.2, including the 'spdep' package [19], was used for all analyses. The study adhered to the tenets of the Declaration of Helsinki for research involving human subjects, and the study protocol was approved by the Polish Ministry of Health, which is entitled by the law of the Republic of Poland to process the National Health Fund data.

\section{Results}

In total, 310,815 individuals with DR were diagnosed in the year 2017 in Poland. Of them, $174,384(56.11 \%)$ were women, 221,144 (71.15\%) lived or had lived in urban areas, and 40,231 (12.94\%) and 270,584 (87.06\%) had type 1 and type 2 DM, respectively. Because $99.8 \%$ of the individuals in the DM population were adults, all the presented statistics were calculated per adult population in Poland. Figure 1 shows the DR prevalence per 10,000 population in the counties of Poland in the year 2017.

There are groups of counties with either high or low values of retinopathy prevalence in Poland in terms of quantiles values. The spatial dependence between the counties was statistically verified with Moran Index I (Figure 2). The I value equalled

Table I. The factors used to explain the differences of the prevalence of diabetic retinopathy in the counties of Poland

\begin{tabular}{|c|c|c|}
\hline Variable & Description & Category \\
\hline DR prevalence & DM prevalence per 10,000 adults in a county & Explanatory variable \\
\hline Income & The median of income in a county & Socio-demographic \\
\hline Age $65+$ & Share of population aged 65 years or more in a county & Socio-demographic \\
\hline Urban living & Share of population living in the urban area in a county & Socio-demographic \\
\hline DM prevalence & DM prevalence per 10,000 adults in a county & Epidemiological \\
\hline DIAB consultations & $\begin{array}{l}\text { The number of diabetes specialist consultations in NHF database } \\
\text { per 10,000 adults in a county }\end{array}$ & Accessibility/quality \\
\hline OPT consultations & $\begin{array}{l}\text { The number of ophthalmological consultations in NHF database } \\
\text { per } 10,000 \text { adults in a county }\end{array}$ & Accessibility/quality \\
\hline DIAB consultations GP & $\begin{array}{l}\text { The number of GP diabetic consultations per 10,000 adults in } \\
\qquad \text { a county }\end{array}$ & Accessibility/quality \\
\hline OPT distance & $\begin{array}{l}\text { The average distance to an ophthalmologist in a county. The } \\
\text { distance was defined as the shortest distance between the centre } \\
\text { of the county of the patient's residence and the centre of the } \\
\text { county of the ophthalmological service }\end{array}$ & Accessibility/quality \\
\hline DIAB distance & $\begin{array}{l}\text { The average distance to a diabetes specialist in a county. } \\
\text { The distance was defined as the shortest distance between the } \\
\text { centre of the county of the patient's residence and the centre of } \\
\text { the county of the diabetic service }\end{array}$ & Accessibility/quality \\
\hline
\end{tabular}


A

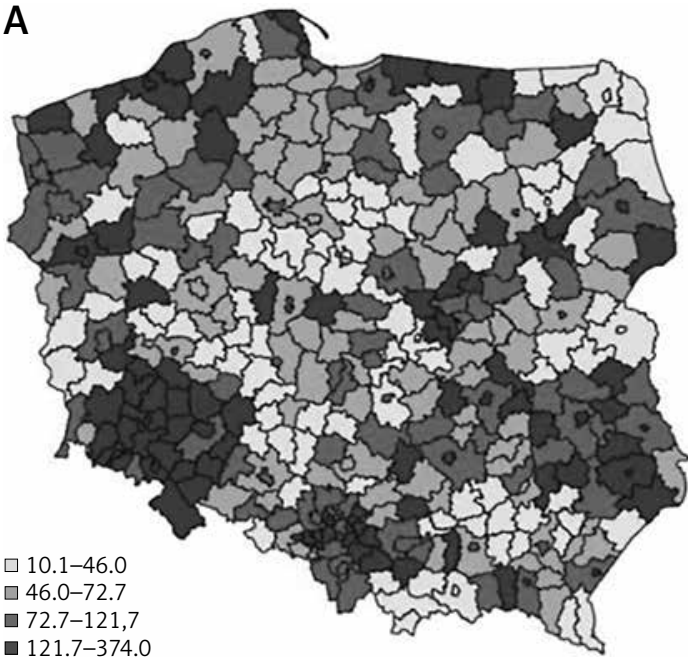

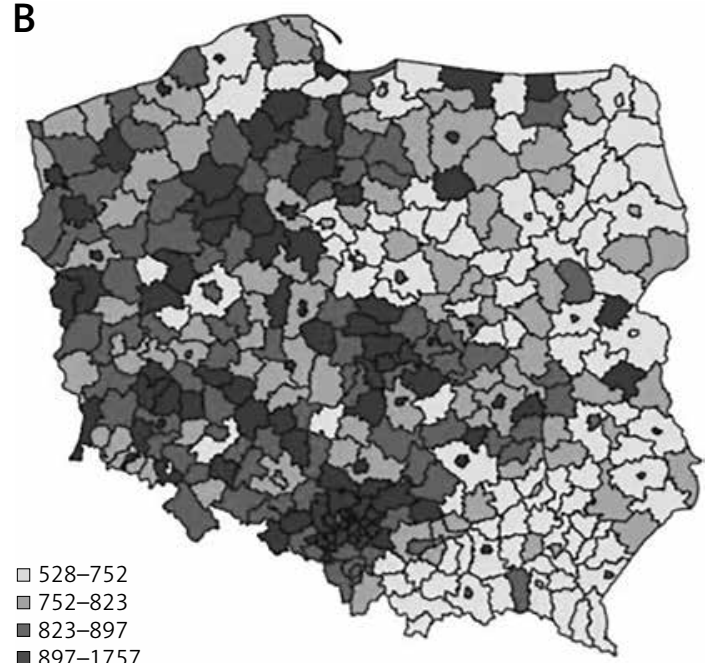

- 897-1757

Figure 1. The prevalence of diabetic retinopathy (A) and diabetes mellitus (B) per 10,000 population in the counties in Poland in 2017

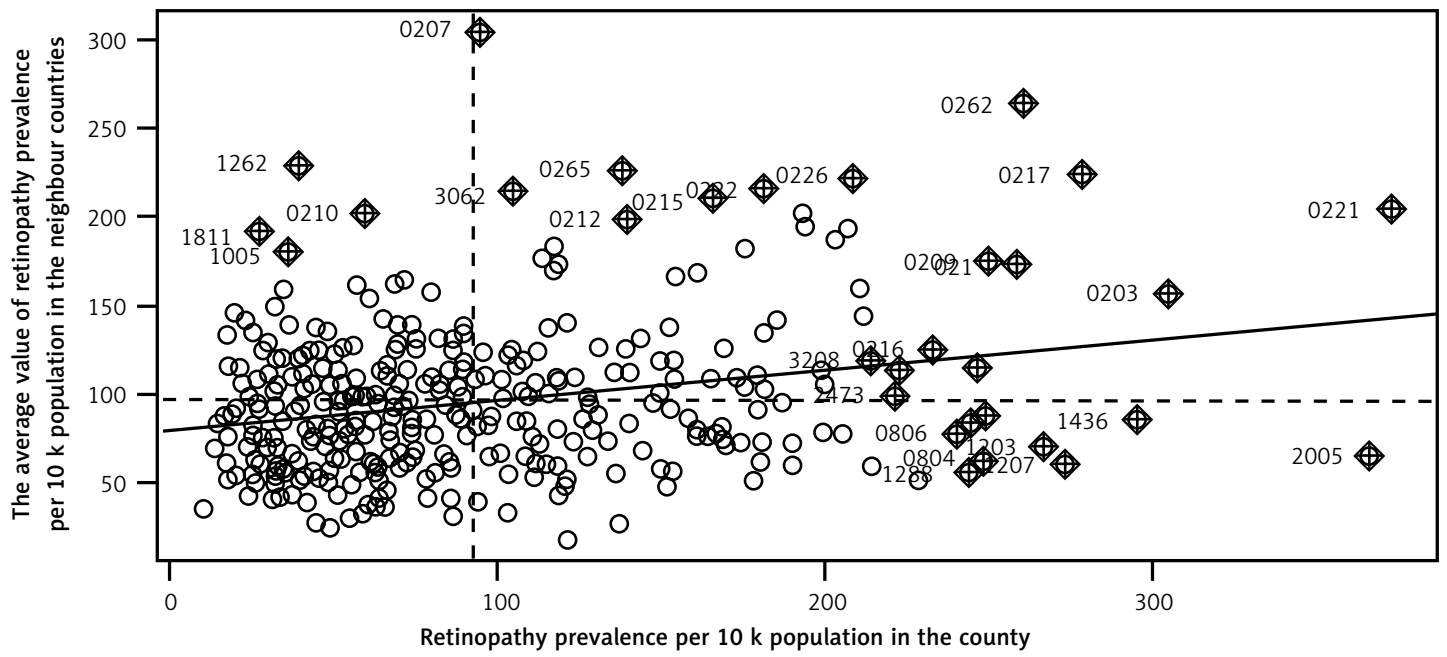

Figure 2. The analysis of spatial dependence between the counties with Moran Index I

0.18 and is statistically significant $(p<0.001)$. The 'hot spots' (the counties of high retinopathy prevalence are surrounded by counties of high retinopathy prevalence) and 'low spots' (groups of counties of low retinopathy prevalence) indicate that the distribution of DR is not random in Poland. The highest DR prevalence occurred in the southwest part of Poland and in many counties of the north and east of Poland. The lowest DR prevalence occurred mainly in the centre of Poland. DM prevalence in Poland also is demonstrated on the map in Figure 1.

Relatively low values of DM prevalence were found in the eastern part of the country in comparison to the western part. To evaluate the factors of retinopathy occurrence in the counties the SAR model was built. The descriptive statistics of each variable used in the model are presented in Table II and indicate the differentiation among counties' values.
The median number of subjects with DM and DR per county was 823.39 and 72.67 , respectively. The median of average earnings among counties was about 3146.48 PLN (804.27 USD), whereas the difference between the richest and the poorest county was shown to be of value about 3825.64 PLN (977.86 USD). The median of the number of diabetic and ophthalmologic consultations per 10,000 adults was 2736.09 and 713.85 , respectively. In addition, access to ophthalmologic and diabetic specialists (measured as the number of consultations per adult population) varied among counties (Figure 3). The analysis of the SAR model showed that average earnings were a significant factor for the occurrence of DR in the counties (Table III). A $10 \%$ increment of income in relation to the income median increased the retinopathy prevalence by $10.9 \%$. In terms of absolute values, an increase in income of about 300 PLN (76.73 USD) in counties caused a increase of DR preva- 
Milena Kozioł, Michał S. Nowak, Beata Koń, Monika Udziela, Jacek P. Szaflik

Table II. The primary statistics of variables used in the SAR model

\begin{tabular}{|lcccc|}
\hline Parameter & $\begin{array}{c}\text { Minimum in the } \\
\text { counties }\end{array}$ & $\begin{array}{c}\text { Median in the } \\
\text { counties }\end{array}$ & $\begin{array}{c}\text { Maximum in the } \\
\text { counties }\end{array}$ & SD in the counties \\
\hline DR prevalence & 10.10 & 72.67 & 373.96 & 64.31 \\
\hline Income & 2487.05 & 3146.84 & 6312.69 & 435.27 \\
\hline Age 65+ & 0.11 & 0.16 & 0.26 & 0.02 \\
\hline Urban living & 0.00 & 0.46 & 1.00 & 0.27 \\
\hline DM prevalence & 527.98 & 823.39 & 1757.17 & 111.95 \\
\hline DIAB consultations & 45.13 & 713.85 & 4154.73 & 615.13 \\
\hline OPT consultations & 146.63 & 2736.09 & 11055.81 & 1660.21 \\
\hline DIAB consultations GP & 435.88 & 1909.48 & 5763.62 & 733.14 \\
\hline OPT distance & 0.00 & 10.83 & 40.74 & 6.17 \\
\hline DIAB distance & 0.00 & 11.34 & 73.97 & 9.98 \\
\hline
\end{tabular}

A

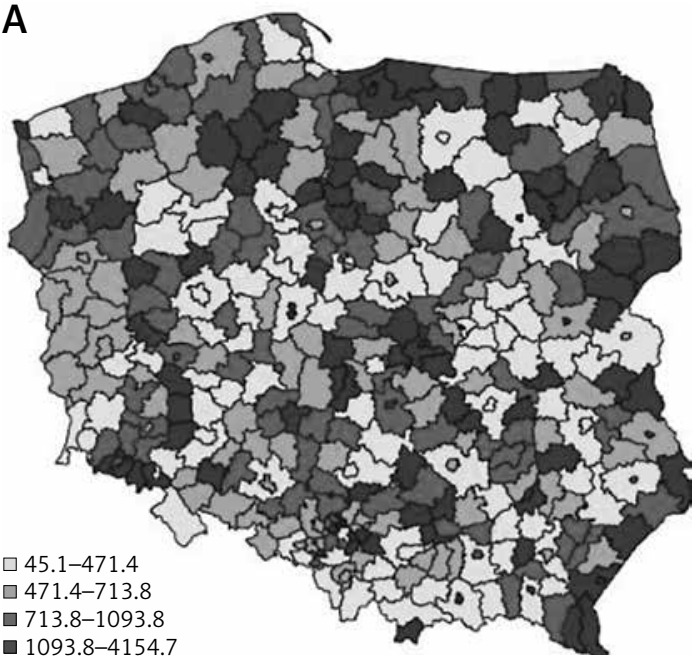

B

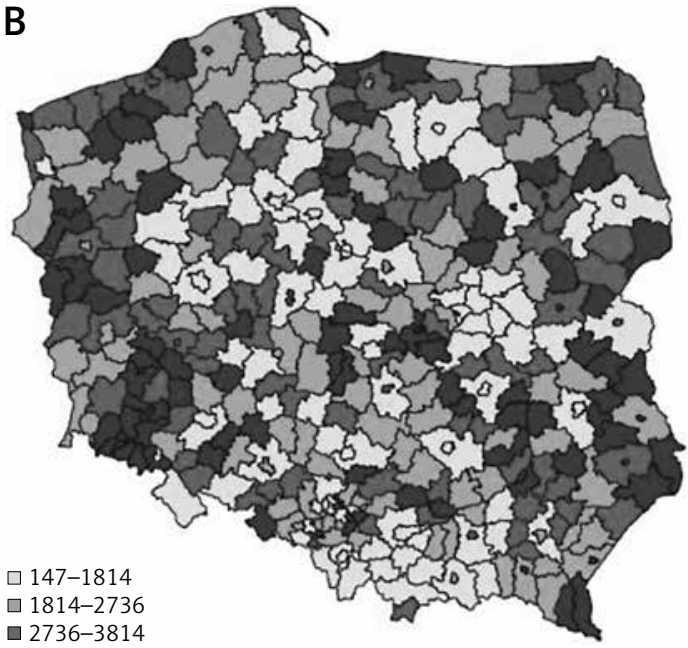

2736-3814

- 3814-11056

Figure 3. The number of diabetic consultations (A) and ophthalmologic consultations (B) per 10,000 adult population in the counties in Poland in 2017

Table III. SAR model results for diabetic retinopathy social and demographic risk factors in the counties of Poland

\begin{tabular}{|lcccc|}
\hline Variable & Coefficient estimate & $\mathbf{2 . 5 \%} \mathrm{Cl}$ & $\mathbf{9 7 . 5 \%} \mathrm{Cl}$ & $P$-value \\
\hline (Intercept) & 0.812 & 0.745 & 0.886 & $<0.001^{*}$ \\
\hline Earnings & 1.109 & 1.041 & 1.182 & $0.001^{*}$ \\
\hline Age 65+ & 1.019 & 0.963 & 1.080 & 0.51 \\
\hline Urban living & 1.000 & 0.983 & 1.017 & 0.995 \\
\hline DM prevalence & 1.110 & 1.047 & 1.176 & $<0.001^{*}$ \\
\hline DIAB consultations & 0.988 & 0.977 & 1.000 & $0.041^{*}$ \\
\hline OPT consultations & 1.022 & 1.006 & 1.038 & $0.007^{*}$ \\
\hline DIAB consultations GP & 1.005 & 0.986 & 1.023 & 0.619 \\
\hline OPT distance & 0.993 & 0.975 & 1.011 & 0.428 \\
\hline DIAB distance & 0.991 & 0.980 & 1.002 & 0.098 \\
\hline
\end{tabular}

*Statistically significant.

lence of 8 per 10,000 adults. The DR prevalence in the county was also highly influenced by the DM prevalence 82 per 10,000 adult people higher DM prevalence in the county causes 7 per 10,000 adult people higher DR retinopathy. Furthermore, the accessibility to medical services proved to be statistically significant. The increase in the number of ophthalmologic consultations according to 
the NHF database per 10,000 adults in a county of $10 \%$ of median (273) resulted in an increase of $2.2 \%$ of the DR prevalence median (1.6 per 10,000 adults). On the other hand, limited access to the diabetic service had the effect of decreased occurrence of DR in the counties. The goodness of the model was verified with $R^{2}$, which was equal to 0.21 .

\section{Discussion}

The vascular (micro- and macroangiopathy) complications of DM are the main cause of morbidity and mortality among the DM population. These complications, such as blindness, chronic renal insufficiency, and amputation of the lower limb, lead to increased mortality rates. In addition, $D M$ is an important risk factor for the onset of Alzheimer's disease, cognitive functional decline, and reduced health-related quality of life $[5,6]$. The application of spatial analytical methods is common among studies concerning the distribution of occurrence of both contiguous and non-contiguous diseases [13, 17-19]. However, the authors did not find any study focusing on spatial analysis of diabetic retinopathy on the national level. This study is based on the overall population of Poland in the year 2017 and presents the geographical characteristics of the prevalence of diabetic retinopathy and co-existing social, demographic, and systemic factors on the county level. The given score of the Moran Index $(0.18, p<0.01)$ indicates that the null hypothesis of complete randomness of the distribution of DR prevalence in Poland is rejected, and it suggests the presence of cluster patterns. The high DR prevalence occurred in the south-west part of Poland, where hotspot counties have been noted. The low DR prevalence occurred mainly in the centre of Poland. The SAR model analyses revealed that the most influential factor on DR prevalence in the counties was DM prevalence, which in Poland is also not random $(I=0.21, p<0.01)$. In addition, in 2017 , relatively lower values of DM prevalence were seen in the eastern part of the country in comparison to the western part. The analysis of the SAR model also showed that average income was the most significant socioeconomic factor for the occurrence of DR in the counties. A higher level of average income resulted in a higher prevalence of DR in the counties of Poland. In contrast, the results of a study from the United Kingdom showed that socioeconomic deprivation was associated with increased DR prevalence in patients with type $1 \mathrm{DM}$. However, this association was not confirmed in patients with type 2 DM [27]. The results of another showed that in Spain socioeconomic status was not significantly associated with DR [28]. However, the multicentre EURODIAB IDDM Complications study showed a higher prevalence of proliferative DR in men with lower educational qualifications compared with those with a higher level of education [29]. The analysis of the socioeconomic status and global diabetes prevalence showed that diabetes prevalence rises with increasing socioeconomic status in developing countries, and this is reversed in developed countries [30]. Although Poland is a middle-income country [31], the Polish pattern of DR and DM prevalence is similar to that found in developing countries. In our study, DR prevalence in the counties was not significantly associated with place of residence, which was in agreement with the results of the study from the United Kingdom, which showed that distance to medical services was not associated with attendance of DR screening [32]. When it comes to the variables describing access to the medical service, a higher number of ophthalmological consultations has the effect of increased occurrence of DR in the counties. The regions with a greater number of ophthalmologic consultations per population are characterized by a greater number of ophthalmologists. This, in turn, indicates that the DR diagnoses are made less often in counties with limited access to ophthalmologists, which agrees with the results of previous studies from the United Kingdom [27]. However, the higher number of consultations in diabetes specialists influences the decreased DR prevalence, the number of diabetic consultations in General Practitioners (GPs) does not affect the DR occurrence in the counties. It shows the differences in the effectiveness of diabetic care in GPs and in diabetic specialists. In Poland, there are counties where the number of diabetic consultations is exceptionally low and high, which indicates great inequalities in diabetic healthcare in the country. Knowing the hotspot and low-spot locations of DR prevalence could influence the prevention program of $D R$. One of the possible actions that can improve the access of DM patients to ophthalmologists is the introduction of telemedicine. In the aspect of DR, telemedicine-based screening of DM patients incorporating artificial intelligence technology has the potential to facilitate more widespread and cost-effective screening, particularly in low- and middle-income countries. Early results showed high diagnostic sensitivity and specificity of such systems in DR screening programs in many countries [33-35].

The limitations of the study concern mostly the data used. NHF data include information provided for all insured people in Poland (in 2017 approx. $89 \%$ of the whole population). The data does not include information about medical services and drugs purchased by non-insured people and outof-pocket finances. However, such mistakes prob- 
ably had only a minor impact on the study findings, because non-insured people are rather poor and do not purchase a lot of medical services in Poland. The population size and national recruitment are the most important strengths of the present study.

In conclusion, geographic information systems with spatial analytical methods are helpful in the study of health status and health care delivery. All social, economic, environmental, and genetic factors may have spatial distributions influencing the prevalence of a particular disease. Our study showed statistically significant differences in the prevalence of DR and DM in the overall population of Poland in the years 2013-2017 on the regional level. This is the first nationwide study of DR in Central Europe on such a low administrative level. The presented results indicate that high DR prevalence occurred in the south-west part of Poland and low DR prevalence occurred mainly in the centre of Poland. The analyses of co-existing social, demographic, and systemic factors revealed that the level of income and access to ophthalmologic and diabetic services are crucial in DR prevalence.

\section{Conflict of interest}

The authors declare no conflict of interest.

\section{References}

1. Cho NH, Shaw JE, Karuranga S, et al. IDF Diabetes Atlas: Global estimates of diabetes prevalence for 2017 and projections for 2045. Diabetes Res Clin Pract 2018; 138: 271-81.

2. Khanam PA, Hoque S, Begum T, Habib SH, Latif ZA. Microvascular complications and their associated risk factors in type 2 diabetes mellitus. Diabetes Metab Syndr 2017; 11 Suppl 2: S577-81.

3. Maric-Bilkan C. Sex differences in micro- and macro-vascular complications of diabetes mellitus. Clin Sci 2017; 131: 833-46.

4. Kayar Y, Agin M. The relationship between demographic and anthropometric characteristics and diabetic complications and number of hospitalizations in hospitalized diabetic patients. Arch Med Sci Civil Dis 2019; 4: e7-15.

5. Navarro-Flores E, Pérez-Ros P, Martínez-Arnau FM, Julían-Rochina I, Cauli O. Neuro-psychiatric alterations in patients with diabetic foot syndrome. CNS Neurol Disord Drug Targets 2019; 18: 598-608.

6. Navarro-Flores E, Cauli O. Quality of life in individuals with diabetic foot syndrome. Endocr Metab Immune Disord Drug Targets 2020; 20: 1365-72.

7. Antonetti DA, Klein R, Gardner TW. Diabetic retinopathy. N Engl J Med 2012; 366: 1227-39.

8. Duh EJ, Sun JK, Stitt AW. Diabetic retinopathy: current understanding, mechanisms, and treatment strategies. JCl Insight 2017; 2: e93751.

9. Flaxman SR, Bourne RRA, Resnikoff S, et al.; Vision Loss Expert Group of the Global Burden of Disease Study. Global causes of blindness and distance vision impairment 1990-2020: a systematic review and meta-analysis. Lancet Glob Health 2017; 5: e1221-34.
10. Sabanayagam C, Yip W, Ting DS, Tan G, Wong TY. Ten emerging trends in the epidemiology of diabetic retinopathy. Ophthalmic Epidemiol 2016; 23: 209-22.

11. Liew G, Wong VW, Ho IV. Mini review: changes in the incidence of and progression to proliferative and sight-threatening diabetic retinopathy over the last 30 years. Ophthalmic Epidemiol 2017; 24: 73-80.

12. Cheloni R, Gandolfi SA, Signorelli C, Odone A. Global prevalence of diabetic retinopathy: protocol for a systematic review and meta-analysis. BMJ Open 2019; 9: e022188.

13. Rosenberg MS, Sokal RR, Oden NL, DiGiovanni D. Spatial autocorrelation of cancer in Western Europe. Eur J Epidemiol 1999; 15: 15-22.

14. Moore DA, Carpenter TE. Spatial analytical methods and geographic information systems: use in health research and epidemiology. Epidemiol Rev 1999; 21: 143-61.

15. Rezaeian M, Dunn G, St Leger S, Appleby L. Geographical epidemiology, spatial analysis and geographical information systems: a multidisciplinary glossary. J Epidemiol Community Health 2007; 61: 98-102.

16. Bivand R. e Spatial Dependence: Weighting Schemes, Statistics. Available at: https://cran.r-project.org/web/ packages/spdep/spdep.pdf (accessed February 1, 2020).

17. Tewara MA, Mbah-Fongkimeh PN, Dayimu A, Kang F, Xue F. Small-area spatial statistical analysis of malaria clusters and hotspots in Cameroon; 2000-2015. BMC Infectious Diseases 2018; 18: 636.

18. Li R, Cheng S, Luo C, et al. Epidemiological characteristics and spatial-temporal clusters of Mumps in Shandong Province, China 2005-2014. Sci Rep 2017; 7: 46328.

19. Turnbull BW, Iwano EJ, Burnett WS, Howe HL, Clark LC. Monitoring for clusters of disease: application to leukemia incidence in upstate New York. Am J Epidemiol 1990; 132 (1 Suppl): S136-43.

20. Nowak MS, Grabska-Liberek I, Michalska-Małecka K, et al. Incidence and characteristics of cataract surgery in Poland, during 2010-2015. Int J Environ Res Public Health 2018; 15: E435.

21. Nowak MS, Grzybowski A, Michalska-Małecka K, et al. Incidence and characteristics of endophthalmitis after cataract surgery in Poland, during 2010-2015. Int J Environ Res Public Health 2019; 16: E2188.

22. Central Statistical Office of Poland Data: Available at http://www.stat.gov.pl (accessed February 1, 2020).

23. The National Health Fund Data. Available at http:// www.nfz.gov.pl (accessed February1. 2020).

24. Mayer JD. The role of spatial analysis and geographic data in the detection of disease causation. Soc Sci Med 1983; 17: 1213-21.

25. Gesler W. The uses of spatial analysis in medical geography: a review. Soc Sci Med 1986; 23: 963-73.

26. Osei FB. Current statistical methods for spatial epidemiology: a review. Austin Biom Biostat 2014; $1: 7$.

27. Low L, Law J, Hodson J, McAlpine R, O'Colmain U, MacEwen $C$. Impact of socioeconomic deprivation on the development of diabetic retinopathy: a population-based, cross-sectional, and longitudinal study over 12 years. BMJ Open 2015; 5: e007290.

28. Larrañaga I, Arteagoitia JM, Rodriguez JL, Gonzalez F, Esnaola S, Piniés JA; Sentinel Practice Network of the Basque Country. Socio-economic inequalities in the prevalence of type 2 diabetes, cardiovascular risk factors and chronic diabetic complications in the Basque Country, Spain. Diabet Med 2005; 22: 1047-53.

29. Chaturvedi N, Stephenson JM, Fuller JH. The relationship between socioeconomic status and diabetes control 
and complications in the EURODIAB IDDM Complications Study. Diabetes Care 1996; 19: 423-30.

30. Xu Z, Yu D, Yin X, Zheng F, Li H. Socioeconomic status is associated with global diabetes prevalence. Oncotarget 2017; 8: 44434-39.

31. GDP per capita in PPS. European Commission Data: Available at http://ez.europa.eu/eurostat (accessed March 15, 2020).

32. Leese GP, Boyle P, Feng Z, Emslie-Smith A, Ellis JD. Screening uptake in a well-established diabetic retinopathy screening program: the role of geographical access and deprivation. Diabetes Care 2008; 31: 2131-5.

33. Lu W, Tong Y, Yu Y, Xing Y, Chen C, Shen Y. Applications of artificial intelligence in ophthalmology: general overview. J Ophthalmol 2018; 2018: 5278196.

34. Wong TY, Sabanayagam C. Strategies to tackle the global burden of diabetic retinopathy: from epidemiology to artificial intelligence. Ophthalmologica 2020; 243: 920.

35. Xu Y, Wang Y, Liu B, et al. The diagnostic accuracy of an intelligent and automated fundus disease image assessment system with lesion quantitative function (SmartEye) in diabetic patients. BMC Ophthalmol 2019; 19: 184. 